\title{
SECOND HARMONIC GENERATION (SHG) FROM THERMALLY POLED Zn-Bi-Te-O-F GLASSES WITH VERY LONG RELAXATION TIME
}

\section{HIROYUKI NASU, DAICHI KINOSHITA, SHYOHEI DEGUCHI, TOSHIKI OKADA, YUKI UEMURA, TADANORI HASHIMOTO and ATSUSHI ISHIHARA}

Division of Materials Science

Graduate School of Engineering

Mie University

Kurima-Machiyamachi 1577

Tsu 514-8507

Japan

e-mail: nasu@chem.mie-u.ac.jp

\begin{abstract}
Second harmonic generation (SHG) was observed from a thermally poled $\mathrm{Zn}-\mathrm{Bi}$ Te-O-F glass system measured by Maker-Fringe pattern using Nd: YAG high power pulse laser. Both $\mathrm{Bi}$ and $\mathrm{F}$ were necessary for the generation, otherwise no SHG was observable from the glasses without Bi or $\mathrm{F}$. The intensity of the generation depended on the F content. In the SHG from poled glasses, short relaxation time has been neck of the practical use. Although the generation of the common thermally poled glasses relaxed within 3 days, for those of the present glasses, the generation was maintained over 1 month. This is considered to be explained by the interaction of the dipoles between the large $\mathrm{Bi}$ ions binding the $\mathrm{F}$ ions inside of glasses.
\end{abstract}

Keywords and phrases: second harmonic generation (SHG), thermally poling, oxyfluoride glasses, bismuth ions, fluorine ions.

Received November 13, 2017

(C) 2018 Scientific Advances Publishers 


\section{Introduction}

Optical nonlinearity has a high potential in future devices for alloptical photonic systems. Mainly, among optical nonlinearity, secondand third-order optical nonlinearities have been extensively studied because of their relatively large magnitude and they cover almost all optical functionality caused by the nonlinearity. Second-order optical nonlinearity had been believed not to be observed in homogeneous substances such as glasses because of macroscopic conditions, to be specific, optical scale isotropic and centrosymmetric structure. However, Myers et al. have reported second harmonic generation from thermally poled silica glasses derived from various routes, and explained that the generation resulted from the migration of mobile ions such as impure sodium ions [1]. We also reported the significant role of $\mathrm{OH}$-ions in glass structure from experiments with SHG from thermally poled silica glasses prepared various techniques including the vapor axial deposition method, sol-gel method and so on [2]. Since then, many works have been extensively carried out concerning the field of the second harmonic generation for homogeneous glasses after special treatment. Some of them are poling under UV light irradiation called photo-induced generation [3], using a seed laser incident beam called optical poling [4], using corona exposure called corona poling [5] or applying external or internal stress [6].

With respect to the mechanism, the orientation of dipoles and the process through $\chi^{(3)}$ induced electrical potential gradient caused by the ion diffusion are still controversial. Since rather fast relaxation of second harmonic generation has been reported in many glasses, the latter explanation is supported by many researchers. However, in the case of Ge-S glass systems, the structure change with the broken bonds and formation of the dangling bonds has been strongly suggested in detail exploration by using such as electronic spin resonance measurement although it shows similar fast relaxation in second harmonic intensity [7]. 
For the influence of halogen ions, the deficiency of halogen ions in cathode side of the glass has been observed in $\mathrm{Br}$ and/or $\mathrm{Cl}$ containing glasses [8] in spite of that cation ions at anode side has been reported in the literature [4, 9-11] and explained by cation diffusion. However, the role of fluorine in second harmonic generation is still unsure. This paper reports very slow relaxation of second harmonic generation in $\mathrm{Zn}-\mathrm{Bi}$-Te$\mathrm{O}-\mathrm{F}$ glass systems and investigates the role of fluorine ions relating to bismuth ions in this phenomena.

Commercially available and analytical grade $\mathrm{ZnO}, \mathrm{ZnF}_{2}, \mathrm{Bi}_{2} \mathrm{O}_{3}$, $\mathrm{BiF}_{3}, \mathrm{BaO}, \mathrm{BaF}_{2}$, and $\mathrm{TeO}_{2}$ powders were used as raw materials. After weighed to $10\left(\mathrm{ZnO}\right.$ or $\left.\mathrm{ZnF}_{2}\right)-20\left(\mathrm{BiO}_{3 / 2}, \mathrm{BiF}_{3}\right)-70 \mathrm{TeO}_{2}(\mathrm{~mol} \%)$ and to $10 \mathrm{ZnF}_{2}-10\left(\mathrm{BiO}_{2 / 3}, \mathrm{BaO}\right)-10\left(\mathrm{BiF}_{3}, \mathrm{BaF}_{2}\right)-70 \mathrm{TeO}{ }_{2}(\mathrm{~mol} \%)$ the powders were mixed well with alumina pestle and mortar.

Subsequently, the mixed powders were placed into alumina crucibles with alumina cups and melted in the electric furnace placed in a globe box filled with nitrogen gas at $800^{\circ} \mathrm{C}$ for $30 \mathrm{~min}$. After the melting operation, the melted product was quenched by sandwiching between iron plates. The quenched bodies were annealed at $400^{\circ} \mathrm{C}$ for $30 \mathrm{~min}$ in air. The appearance of the obtained bodies is colorless and transparent. The glasses were cut and polished to about $1 \mathrm{~mm}$ thickness and finished to optical grade. Au electrodes were deposited on the both sides of the polished glass plates by using vapor deposition equipment in order to ensure good electric contact glasses and stainless steel electrodes. The samples were mechanically put in to a DC electrical circuit by pressing stainless steel electrodes. Then, DC voltage of $2 \mathrm{kV}$ was applied for $2 \mathrm{~h}$ at $200^{\circ} \mathrm{C}$. Subsequently, glasses thermally poled were cooled down to room temperature with continuing to apply $2 \mathrm{kV}$. The Au electrodes were wiped off by acetone. After removing electrodes, the transparency and appearance were checked by eye. The intensities of second harmonic generation were determined from the magnitude of the Maker Fringe patterns obtained. The light source was a Q-switched Nd: YAG pulse 
laser operating at the wavelength of $1064 \mathrm{~nm}$. The pulse width and repetition rate of the laser were $10 \mathrm{~ns}$ and $10 \mathrm{~Hz}$, respectively. The incident beam irradiated a samples surface which is rotated around an axis perpendicular to the incident beam direction to change optical length through the samples. The second harmonic intensity was recorded as a function of incident beam angle. Y-cut quartz was used as a reference for second harmonic generation intensity, which was defined as 100.

Figure 1 shows the time dependent relaxation of $\mathrm{SH}$ intensity of $10 \mathrm{ZnO} \cdot 20 \mathrm{BiF}_{3} \cdot 70 \mathrm{TeO}_{2}$ glass. Although $\mathrm{SH}$ intensity weakened with time, the $\mathrm{SH}$ peaks were observable even after $72 \mathrm{~h}$ from thermal poling operation. That is notably slow relaxation compared to other glass systems including chalcogenide glasses [7]. 
1h after poling

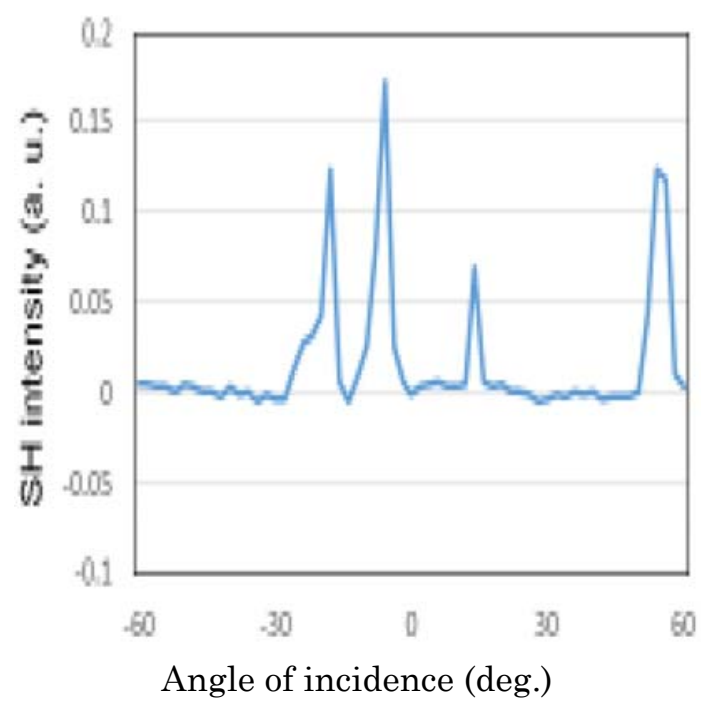

(a)

$24 \mathrm{~h}$ after poling

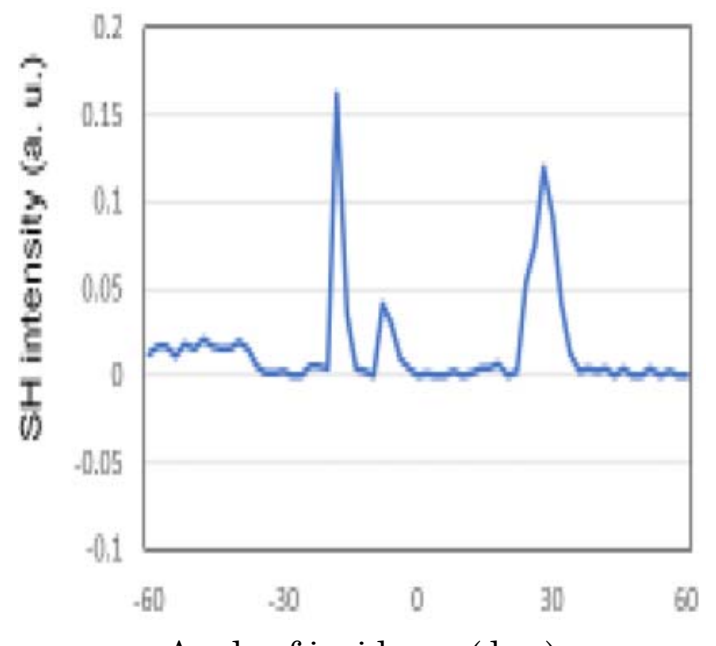

Angle of incidence (deg.)

(b) 


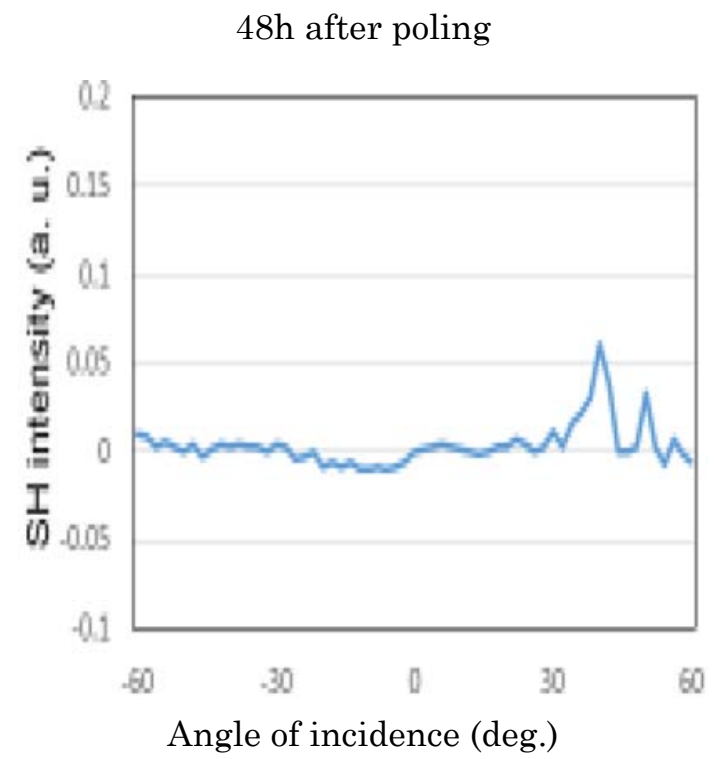

(c)

$72 \mathrm{~h}$ after poling

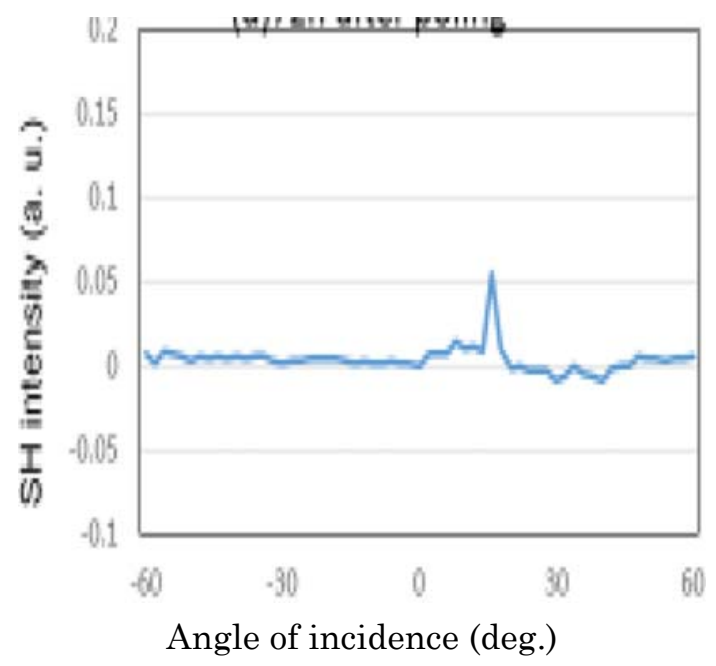

(d)

Figure 1. Relaxation behaviour of second-harmonic intensity for $10 \mathrm{ZnO} \cdot 20 \mathrm{BiF}_{3} \cdot 70 \mathrm{TeO}_{2}(\mathrm{~mol} \%)$. 
Then, we tried to investigate the origin of the slow relaxation of the glass system. Thus, a $\mathrm{F}$-free $10 \mathrm{ZnO} \cdot 20 \mathrm{BiO}_{3 / 2} \cdot 70 \mathrm{TeO}_{2}$ glass was prepared are thermally poled. As a result, no SH generation was detected from the glass even $1 \mathrm{~h}$ after thermal poling. On the other hand, we also prepared a $\mathrm{Bi}$-free glass as $10 \mathrm{ZnO} \cdot 10 \mathrm{BaO} \cdot 10 \mathrm{BaF}_{2} \cdot 70 \mathrm{TeO}_{2}$. In the same way, no oscillation in the Maker-Fringe pattern is seen even $1 \mathrm{~h}$ after the thermal poling

Figure 2 depict the SH intensity 20 days and 30 days after poling. In all present samples, the slow relaxation of $\mathrm{SH}$ makes it possible to see the $\mathrm{SH}$ generation over 30 days. 
20 days after poling

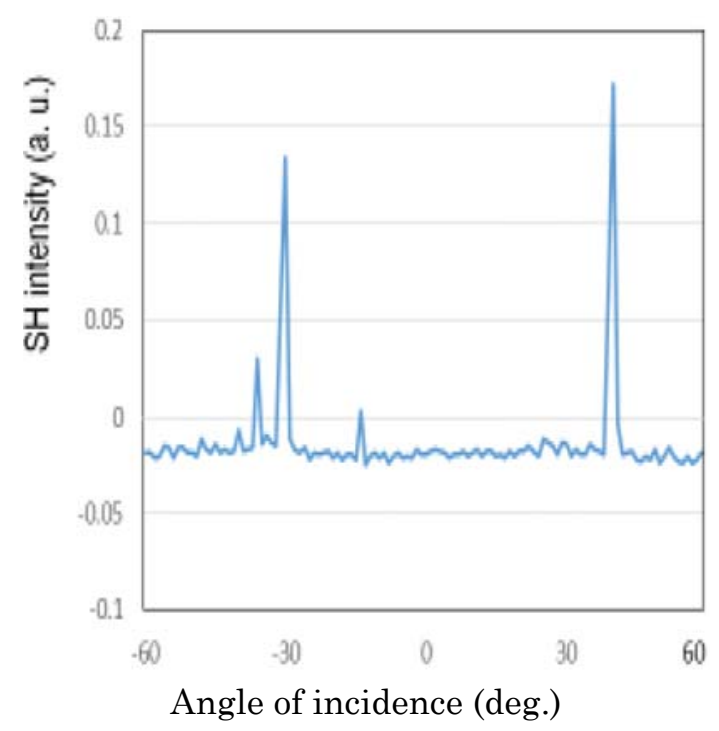

(a)

30 days after poling

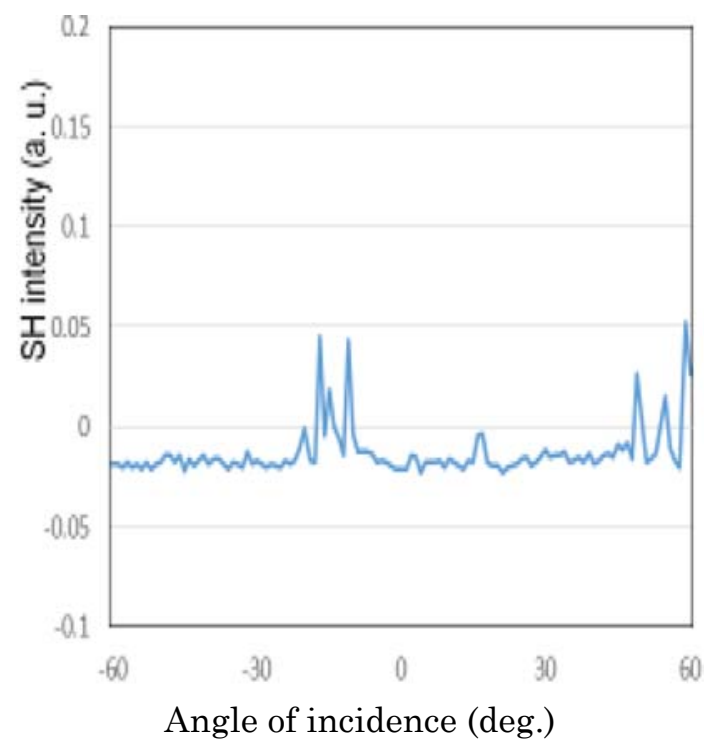

(b)

Figure 2. Relaxation behaviour of second-harmonic intensity for $10 \mathrm{ZnF}_{2} \cdot 20 \mathrm{BiF}_{3} \cdot 70 \mathrm{TeO}_{2}(\mathrm{~mol} \%)$. 
From the results for F-free glass and Bi-free glass, it can be said the existence of both $\mathrm{Bi}$ and $\mathrm{F}$ together is indispensable for $\mathrm{SH}$ stable generation. Further, compared with other glass systems, the combination $\mathrm{Bi}-\mathrm{F}$ elongates the $\mathrm{SH}$ generation over 1 month. Figure 3 plots $\mathrm{SH}$ intensities as a function of $\mathrm{F}$ content. Without $\mathrm{F}$, no $\mathrm{SH}$ generation was detected in this figure, and the existence of $\mathrm{F}$ seems to create $\mathrm{SH}$ generation, and it is elucidated that higher $\mathrm{F}$ content results in higher $\mathrm{SH}$ intensities at any duration after poling. Thus, F content is obviously said that quite important for $\mathrm{SH}$ intensity. But, F cannot cause strong and slow relaxation of $\mathrm{SH}$ intensity only by itself since no $\mathrm{SH}$ was detected from Bi-free glass.

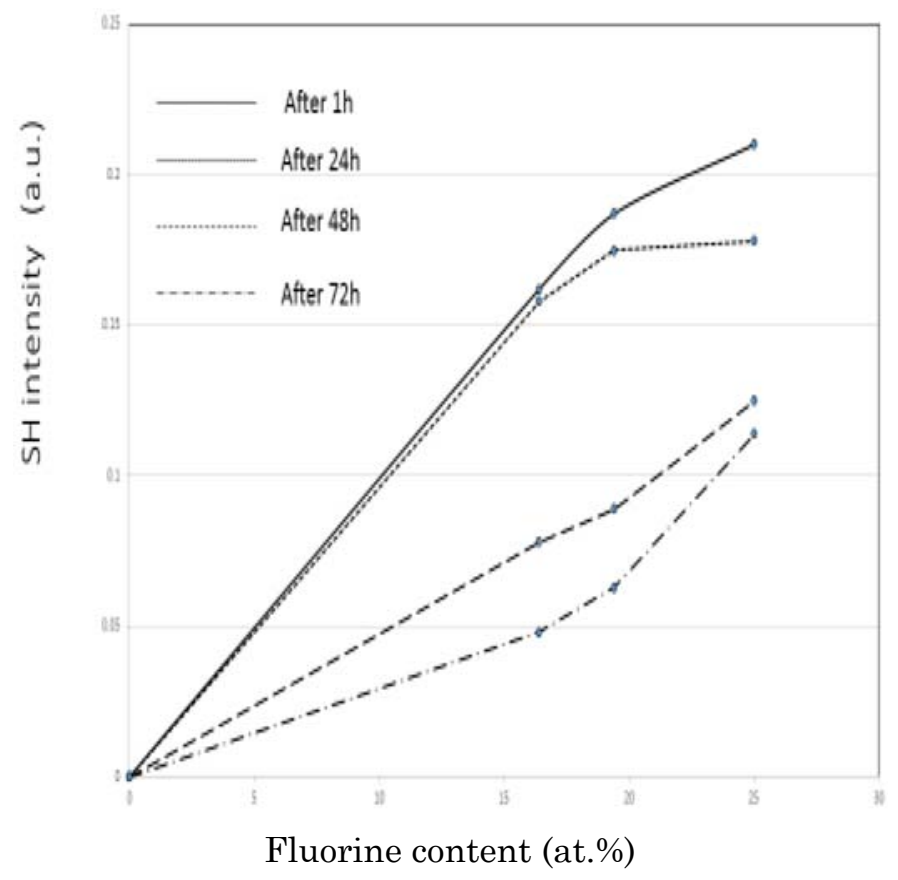

Figure 3. Relaxation behaviour of second-harmonic intensity for $\mathrm{Zn}$-BiTe-O-F glasses. 
Figure 4 shows the time dependence of $\mathrm{SH}$ intensities for $\mathrm{F}$ containing glasses. The strongest $\mathrm{SH}$ intensitiesat any time was observed in the highest $\mathrm{F}$ containing glass, and slower relaxation can be seen the highest $\mathrm{F}$ containing glass as well. It can be pointed out no maximum was observed in $\mathrm{F} / \mathrm{Bi}$ ratio.

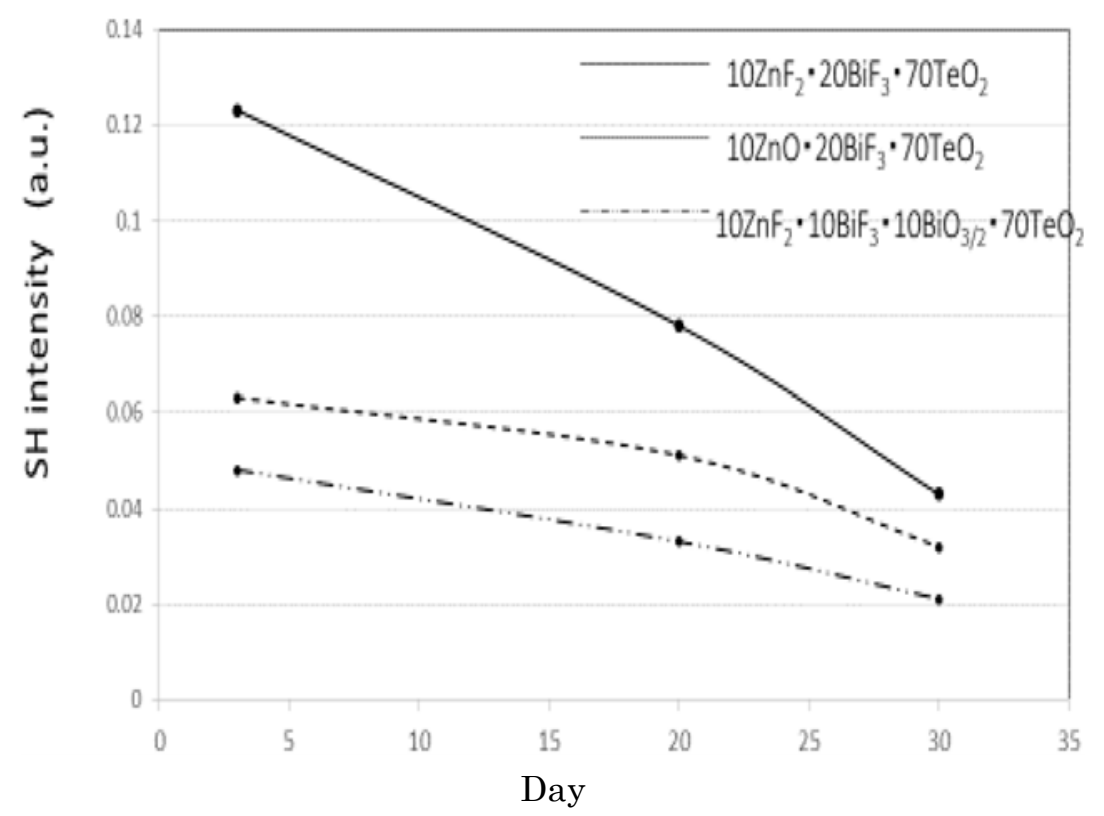

Figure 4. Relaxation behaviour of second-harmonic intensity for $\mathrm{Zn}-\mathrm{Bi}$ Te-O-F glasses.

From the theory of the $\mathrm{SH}$ generation results from ion migration, it cannot explainable why small $\mathrm{F}$ plays an important role. It might be considered the dipole of $\mathrm{Bi}$ and $\mathrm{F}$ interacts and stabilizes the poled structure.

In summary, SHG was successfully obtained from thermally poled $\mathrm{Zn}-\mathrm{Bi}-\mathrm{Te}-\mathrm{O}-\mathrm{F}$ glass system. Although very long relaxation time was observed in SH intensity of the glass, no $\mathrm{SH}$ generation was observable for $\mathrm{F}$-free and $\mathrm{Bi}$-free glasses. It means the combination of $\mathrm{Bi}$ and $\mathrm{F}$ seems to play a significant role of the $\mathrm{SH}$ origin. The relaxation elongates over 1 month, and the $\mathrm{SH}$ intensity and relaxation time depend on $\mathrm{F}$ 
content, and higher SH intensity and longer relaxation time result from higher content of F. It may be caused by the combination of dipole interaction between $\mathrm{Bi}$ and $\mathrm{F}$. Further exploration comes to necessary for the structure of the glasses.

\section{References}

[1] R. A. Myers, N. Mukherjee and S. R. J. Brueck, Large second-order nonlinearity in poled fused silica, Opt. Lett. 16(22) (1991), 1732-1734.

DOI: https://doi.org/10.1364/OL.16.001732

[2] H. Nasu, H. Okamoto, A. Mito, J. Matsuoka and K. Kamiya, Influence of the $\mathrm{OH}$ content on second harmonic generation from electrically polarized $\mathrm{SiO}_{2}$ glasses, Jpn. Appl. Phys. 32 (1993), L406-L407.

DOI: https://doi.org/10.1143/JJAP.32.L406

[3] T. Fujiwara, M. Takahashi and A. Ikushima, Defect formation in $\mathrm{GeO}_{2}-\mathrm{SiO}_{2}$ glass by poling with ArF laser excitation, Appl. Phys. Lett. 71 (1997), 993-995.

DOI: https://doi.org/10.1063/1.119749

[4] J. Si, K. Kitaoka, J. Qui, T. Mitsuyu and K. Hirao, Optically encoded secondharmonic generation in germanosilicate glass by a fem to second laser, Opt. Lett. 24(13) (1999), 911-913.

DOI: https://doi.org/10.1364/OL.24.000911

[5] A. Okada, K. Ishii, K. Mito and K. Sasaki, Second-order optical nonlinearity in corona-poled glass films, J. Appl. Phys. 74 (1993), 531-535.

DOI: https://doi.org/10.1063/1.355265

[6] H. Guignard, V. Nazabal, J. Troles F. Smektala, H. Zeghlache, Y. Quiquempois, A. Kudlinski and G. Martinelli, Second-harmonic generation of thermally poled chalcogenide glass, Optics Express 13(3) (2005), 789-795.

DOI: https://doi.org/10.1364/OPEX.13.000789

[7] Y. Nakane, H. Nasu, J. Heo, T. Hashimoto and K. Kamiya, Second harmonic generation from thermally poled Ge-S glass system, J. Ceram. Soc. Jpn. 113(1323) (2005), 728-732.

DOI: https://doi.org/10.2109/jcersj.113.728

[8] H. Nasu, Y. Nagaike, H. Takeda, T. Hashimoto and K. Kamiya, Second harmonic generation of thermally poled $\mathrm{ZnCl}_{2}-\mathrm{B}_{2} \mathrm{O}_{3}-\mathrm{TeO}_{2}$ glasses and its mechanism, Jpn. J. Appl. Phys. 44 (2005), L964-L965.

DOI: https://doi.org/10.1143/JJAP.44.L964 
[9] A. Narasaki, K. Tanaka, K. Hirao and N. Soga, Induction and relaxation of optical second-order nonlinearity in tellurite glasses, J. Appl. Phys. 85 (1999), 2046-2051.

DOI: https://doi.org/10.1063/1.369500

[10] K. Tanaka, A. Narazaki and K. Hirao, Large optical second-order nonlinearity of poled $\mathrm{WO}_{3}-\mathrm{TeO}_{2}$ glass, Opt. Lett. 25(4) (2000), 251-253.

DOI: https://doi.org/10.1364/OL.25.000251

[11] S. Faez, P. M. Johnson, D. A. Mazurenko and Ad Lagendijk, Experimental observation of second-harmonic generation and diffusion inside random media, J. Opt. Soc. Amer. B 26(2) (2009), 235-243.

DOI: https://doi.org/10.1364/JOSAB.26.000235 